\title{
Recursos y prácticas transmedia en el ámbito educativo
}

María Luisa Zorrilla Abascal*

DOI: https://doiorg/10.17230/9789587206289ch2

\section{Introducción}

Cuando se habla de transmedia, por lo general se piensa en las grandes franquicias del entretenimiento como La Guerra de las Galaxias o Juego de Tronos. Sin embargo, no es común asociar el adjetivo de transmedia con los recursos educativos y se cree que la principal razón para ello es porque son muy pocos los contenidos educativos transmedia disponibles, y aún más escasos en idioma español. Así las cosas, el propósito de este artículo es proponer el diseño de experiencias educativas transmedia como una vía para aprovechar dicha tendencia en la esfera educativa, sin depender necesariamente de la disponibilidad de recursos educativos creados o producidos bajo la etiqueta "transmedia".

Por otra parte, el presente trabajo es el resultado de más de diez años de seguimiento a la noción de lo transmedia en el ámbito educativo. La exploración inició con un proyecto de investigación realizado entre 2005 y 2008 en el Reino Unido, cuyo principal objetivo fue analizar y documentar las relaciones intertextuales en diferentes recursos educativos de $B B C$ Schools, principalmente en los soportes televisivo y web. De este proyecto surgió la propuesta de una taxonomía de intertextualidades transmedia (Zorrilla, 2008, 2016a), la cual propone diez tipos de intertextualidad transmedia en productos educativos que comentaremos más adelante.

El acercamiento a los recursos educativos transmedia derivó en la inquietud por experimentar más allá de los productos y de las experiencias a cargo de terceros. Así, en 2014 la autora de este trabajo publicó, con apoyo del Consejo Nacional para la Cultura y las Artes (CONACULTA), una novela transmedia para lectores adolescentes titulada La flauta de

* Licenciada en Comunicación de la Universidad del Noreste-Tamaulipas, México-, magíster en Comunicación de la Universidad Autónoma de México y doctora en Educación de la Universidad East Anglia, Inglaterra. Profesora investigadora del Instituto de Ciencias de la Educación de la Universidad Autónoma del Estado de Morelos, México. Correo electrónico: maria.zorrilla@uaem.mx 
Acuario (Zorrilla, 2014). Se denominó transmedia porque consta de tres soportes mediáticos: el libro impreso, el diario en línea de la protagonista y un artefacto web, denominado "el dúo digital" que forma parte de la propia narrativa.

En 2015-2016 se presentó la oportunidad de poner a prueba algunos supuestos que habían emergido en torno a las experiencias educativas transmedia y, mediante un apoyo SEP-CONACYT, ${ }^{1}$ se llevó a cabo el proyecto denominado "Fomento a la lectura y reflexión inclusiva a través de narrativas transmedia". ${ }^{2}$ Algunos resultados preliminares de este proyecto se han presentado en diversos foros. En esta ocasión, el propósito es perfilar una propuesta propia de lo transmedia en el campo educativo, a partir de la confluencia de las experiencias antes referidas.

\section{Lo esencial en el concepto de transmedia ${ }^{3}$}

Resulta difícil plantear la posibilidad de la transmedia educativa si no tomamos como punto de partida el origen del término "transmedia", el cual se asocia en su origen a las narrativas, en el contexto de las industrias culturales y del entretenimiento.

Si bien Marsha Kinder (1991) fue la primera en acuñar el término “intertextualidades transmedia”, es Henry Jenkins quien popularizó la noción de narrativa transmedia y quien ha venido trabajando el concepto desde 2003 con el propósito de definir sus elusivos contornos. En su libro Convergence Culture de 2006 encontramos una de las definiciones de transmedia más citadas: "Una historia transmedia se desarrolla a través de múltiples plataformas mediáticas, en donde cada nuevo texto hace una contribución distintiva y valiosa al todo. [...] Cualquier producto dado es un punto de entrada a la franquicia como un todo" (2006, pp. 95-96). ${ }^{4}$

En esa fase de su construcción conceptual, Jenkins destaca dos aspectos que consideramos medulares:

- Cada elemento o producto de la franquicia debe contribuir con algo nuevo o diferente al desarrollo de la historia.

1 La sigla SEP corresponde a la Secretaría de Educación Pública, en México, y CONACYT al Consejo Nacional para la Ciencia y la Tecnología.

2 Proyecto de Intervención en Educación Básica SEP/CONACYT 2013: N. 231304.

3 Este apartado es un resumen del Marco teórico de la ponencia de Zorrilla (2016b).

4 Todas las traducciones de los textos en inglés son de la autora. 
- Los elementos narrativos de la franquicia pueden provenir de la entidad productora (empresa mediática), pero también pueden ser generados por los seguidores (fans), lo que se conoce como fan fiction o fanfic.

Este segundo elemento también es señalado por Pratten, quien afirma que la narrativa transmedia es una forma de contar una historia a través de múltiples medios y preferiblemente, aunque no siempre sucede, con un grado de participación, interacción o colaboración del público (Pratten, 2011, p. 1).

Carlos Scolari (2009) analiza el concepto de transmedia y otros asociados, como cross-media, plataformas múltiples, medios híbridos, multimodalidad, intermedia, entre otros, e identifica cuatro estrategias para la expansión de mundos ficticios: creación de microhistorias intersticiales, historias paralelas, historias periféricas y contenido generado por los usuarios.

Scolari también refiere el aporte de nuevos ángulos a la historia a través de sus diferentes soportes mediáticos, así como la cocreación por parte de los lectores, entendida la noción de "lector" en un sentido amplio que abarca todas las posibilidades de lectura mediática.

\section{Metodología}

Dado que el presente artículo se nutre de dos proyectos de investigación y una experiencia de creación transmedia, a continuación se resume el abordaje metodológico de cada uno de estos insumos.

El proyecto de identificación y análisis de las intertextualidades transmedia se diseñó a partir de los estudios culturales, por lo que los productos y las prácticas se estudiaron desde tres ángulos: a) el de la producción, a partir de entrevistas con directores y productores de BBC Schools; b) el de los productos culturales, que se enfocó en el análisis textual de recursos televisivos y web de $B B C$ Schools; y c) el de los usos, que se trabajó a partir de observación participante en dos escuelas en el Reino Unido, con docentes y estudiantes de diferentes niveles de educación básica en el ciclo escolar 2006-2007.

La experiencia de creación transmedia abarcó la conceptualización de la obra, su escritura y una participación directa en el proceso de producción para los diferentes soportes mediáticos. Ello se llevó a cabo de 
2012 a 2014. El producto fue la obra denominada La flauta de Acuario: Una novela transmedia (2014).

El proyecto de intervención-investigación en una escuela secundaria en torno a la lectura de la obra antes mencionada, se diseñó para que tuviera dos dimensiones transmedia: 1 ) el producto, es decir, la propia novela transmedia; y 2) la experiencia de consumo, la cual también se diseñó como transmedia, a partir de un círculo de lectura enriquecido que se efectuó a lo largo de seis semanas con tres grupos de segundo año de secundaria, en la ciudad de Cuernavaca, en forma presencial, y con el apoyo de un grupo cerrado en Facebook. Esto se llevó a cabo en el ciclo escolar 2014-2015. La metodología en este proyecto fue la de una intervención educativa (investigación basada en el diseño o DBR, por sus siglas en inglés), documentada a través de la observación participante en las sesiones presenciales y la e-observación en las actividades de Facebook.

\section{Resultados}

Los resultados de la primera fase de investigación en el Reino Unido se presentan en Zorrilla (2008; 2011; 2016a). En este trabajo nos enfocamos en la relevancia de estos resultados previos para los procesos de creación y lectura de la novela transmedia en los proyectos 2012-2014 y 2015-2016. Cabe señalar que la autora del presente trabajo adelanta actualmente la edición de una segunda novela, que es continuación de la primera, también a partir de un diseño transmedia.

Zorrilla $(2008$; 2016a) propone una tipología de intertextualidades transmedia en contenidos educativos que incluye diez tipos. De estos, cinco representan oportunidades de amplificar o transformar el contenido del denominado texto nuclear: expansión, complementación, reproposición (Repurposing), transmutación y generación. Cuatro tipos se identifican como formas de intertextualidad transmedia reiterativa (lo que Jenkins denomina redundante), a saber: resumen, repetición, imitación y referencia, que, aunque proscritas en las narrativas transmedia de las industrias culturales y del entretenimiento, en educación pueden cumplir funciones de reforzamiento y síntesis por su valor intrínseco en los procesos de aprendizaje. Por último, como décimo tipo, está la inconsistencia, que puede ser el resultado de errores en la producción, pero también es una forma intencional de presentar diferentes voces o ángulos en un contenido. 
La novela transmedia La flauta de Acuario se construyó a partir de varias premisas que respondían a diferentes objetivos del proyecto.

Su principal propósito es la promoción de la lectura entre el público adolescente a partir de una experiencia transmedia. Por tanto, a diferencia de las franquicias comerciales, en este producto la puerta de entrada obligada es el libro impreso. En él se encuentran las claves para tener acceso a los contenidos web.

Un segundo objetivo es proveer elementos detonadores para una reflexión sobre la inclusión social de personas con discapacidad. Si bien el personaje protagónico de la obra y la forma en que es introducido responden a este propósito, el cumplimiento y evaluación del mismo requieren el acompañamiento del lector, a partir de una estrategia como la del círculo de lectura enriquecido.

El tercer objetivo es promover nuevas literacidades entre los adolescentes, incluida la navegación transmedia (Jenkins, Purushotma, Weigel, Clinton, \& Robison, 2009) y la cocreación en diferentes soportes mediáticos (Jenkins, Ford, \& Green, 2013). Su logro y evaluación también requerían una estrategia de acompañamiento.

Es en este punto donde se entrecruzan la novela como creación transmedia y el círculo de lectura enriquecido como experiencia transmedia.

A continuación se discuten y comentan los principales resultados de esta intervención-investigación, agrupados en tres aspectos: las diferentes prácticas y trayectorias de lectura transmedia; algunos rasgos de los productos transmedia que pueden generar diferentes experiencias de lectura, y el diseño e implementación de una experiencia educativa transmedia.

\section{Prácticas y trayectorias de lectura transmedia}

Si bien la premisa original del libro impreso como puerta de entrada a la historia se sostuvo, dado que el acceso a los contenidos web depende de la identificación de las claves en el componente impreso, lo que no necesariamente se sostuvo fue la trayectoria de lectura sugerida por la autora o incluso la propia transmedialidad de la obra.

Al final de determinados capítulos del libro, la autora sugiere al lector que puede consultar ciertas fechas del diario de Sara o determinados recuerdos almacenados en el dúo digital, puesto que ya cuenta con la información necesaria para identificar las claves de acceso. 
Sin embargo, la interacción con los 75 jóvenes lectores participantes en el círculo de lectura enriquecido permitió identificar que las prácticas y las trayectorias de lectura fueron muy variadas. Para recuperar esta información se aplicó un cuestionario que respondieron 72 de los 75 participantes, cuyos resultados se reportan en la Figura 1.

Figura 1. Prácticas y trayectorias de lectura transmedia

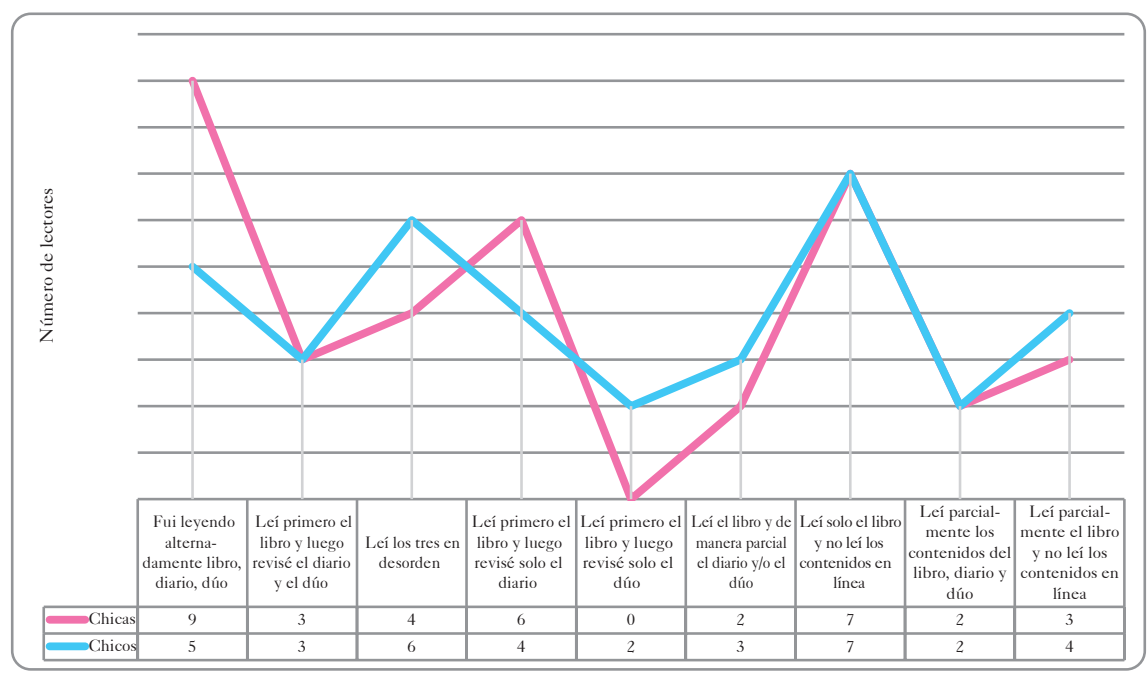

Fuente: Elaboración propia a partir del análisis de datos de la encuesta aplicada a los participantes.

Al ser igual el número de mujeres y hombres que participaron, es posible identificar en este grupo algunas diferencias de género en la aproximación a la lectura. Las mujeres fueron más "dóciles" en seguir el flujo transmedia propuesto por la autora; en contraste, se aprecia que fueron más los hombres que alternaron en forma desordenada la lectura de lo impreso y los componentes web, es decir, que siguieron su propia trayectoria transmedia. Este "desorden" provocó en varios casos que intentaran abrir contenidos web para los que no disponían de las claves, lo cual generó frustración y abandono de la lectura de dichos componentes. También se aprecia que hubo más mujeres que leyeron todo el libro primero y luego revisaron el diario, sin leer el dúo, a diferencia de los hombres, en donde hubo algunos que leyeron todo el libro y después solo revisaron el dúo, situación que no se presentó entre las mujeres. 
Esto es congruente con la naturaleza de los propios contenidos, pues el diario como producto es comúnmente asociado con lo femenino, y, dado que la protagonista es una joven adolescente, el tono y las confidencias del diario fueron más del agrado de las chicas que de los chicos. El dúo en cambio, tiene más una lógica de videojuego y en la propia narrativa es desarrollado por dos jóvenes adolescentes, por lo que es natural que haya despertado más interés entre los chicos.

La premisa del libro como puerta de entrada tuvo como resultado una mayor tasa de lectura del libro que de los soportes web. Varios participantes explicaron que no consultaron los contenidos en línea (o que solo consultaron algunos) porque no disponían de conectividad o de un dispositivo apropiado para la lectura en el momento en que estaban leyendo el libro impreso. Otros expresaron que se "picaron" leyendo el libro y olvidaron consultar los componentes web.

Lo expuesto indica que aun cuando el autor establezca una trayectoria de lectura, el consumo depende del gusto, el interés y la circunstancia del lector.

Algunos rasgos de los productos transmedia que pueden generar diferentes experiencias de lectura

Los resultados antes comentados se relacionan con las prácticas de lectura transmedia, pero también están íntimamente asociados al propio diseño de la obra.

La narrativa en el libro se construyó como un producto "standalone", es decir, que pudiera sostenerse sin la contribución de los contenidos web. Esto precisamente en anticipación a la posibilidad de que los lectores no pudieran acceder a los contenidos web por alguna razón.

Las intertextualidades transmedia entre libro y diario y libro y dúo se construyeron a partir de la tipología propuesta por Zorrilla (2008; 2016a):

El diario de Sara permite una intertextualidad transmedia expansiva, pues presenta información nueva y diferente que no está en la novela, desde la voz y el punto de vista de la protagonista. Algunas entradas del diario llevan incluso a contenidos web externos a la obra. El formato del diario es multimedia, pues incluye texto, imágenes y audio (grabaciones hechas por Sara).

El dúo digital permite dos tipos de intertextualidad transmedia: síntesis y transmutación. Representa la síntesis, porque es un resumen de 
recuerdos que está construyendo Sara para un futuro lector hipotético; es transmutación porque constituye en sí mismo la digitalización de un objeto mágico que en la novela se presenta como de naturaleza material y que forma parte de la propia narrativa. En su formato es multimedia, pues incluye texto e imágenes.

En una creación transmedia, incluir un producto standalone -es decir, que lleva el mayor peso de la narrativa y funciona para el lector incluso sin consultar los otros soportes mediáticos- puede resultar contraproducente y operar en contra de la lectura transmedia, pues hay lectores que optan por prescindir de los medios que consideran periféricos o accesorios. En contraste, generar una fuerte interdependencia entre los diferentes soportes puede derivar en una lectura fragmentaria que obliga al lector a moverse entre plataformas, cuando no necesariamente desea pasar de un cómodo sofá en el que está leyendo un libro o un cómic, a sentarse frente a una pantalla, lo que a su vez puede provocar frustración si no le es posible continuar la lectura debido a la carencia en el momento de un dispositivo tecnológico o de conectividad a la internet.

La autora ha procurado capitalizar lo aprendido en la creación de la siguiente entrega de esta saga, El abanico de Libra, donde si bien el libro impreso es nuevamente un producto standalone, se da mayor peso narrativo al diario de Sara, reforzando su rol expansivo. También se da mayor importancia al dúo digital, que contribuye con intertextualidades transmedia de síntesis, expansión, complementación y transmutación.

Diseño e implementación de una experiencia educativa transmedia Si bien en las industrias culturales y del entretenimiento hay experiencias transmedia como las atracciones vinculadas a Harry Potter o La Guerra de las Galaxias en los parques temáticos, en general lo transmedia está más vinculado a productos que a experiencias.

En nuestra investigación encontramos que, en el campo educativo, sucede lo contrario: es más factible encontrar experiencias transmedia que productos transmedia.

Lo anterior probablemente se debe a que la generación de productos transmedia originales, como algunos de la BBC analizados por Zorrilla (2008; 2016a), requiere importantes inversiones que son poco usuales en el ámbito educativo, especialmente en América Latina. 
Por tanto, para llevar lo transmedia a las aulas como recurso educativo, resulta más viable diseñar experiencias transmedia que generar productos transmedia.

Aunque la investigación realizada en Cuernavaca en torno a la lectura de La flauta de Acuario partió de un producto transmedia creado ex profeso, como se puede apreciar en el apartado de prácticas y trayectorias de lectura transmedia, la experiencia transmedia no sucede por decreto del autor ni se da necesariamente en la forma concebida por este.

Sin embargo, la experiencia puede generarse a partir del propio acompañamiento de la lectura, como sucedió en la intervención-investigación realizada, mediante el diseño de un dispositivo transmedia. Dicho dispositivo fue el círculo de lectura enriquecido, y se denomina transmedia dado que fluyó entre sesiones presenciales cara-a-cara para discutir la lectura del libro y actividades en línea, en Facebook, cuya finalidad era detonar la creatividad de los participantes en torno a la propia lectura, para que generaran productos originales en diferentes formatos, principalmente textos e imágenes.

Las actividades en línea buscaban emular experiencias similares a las de la creación fanfic. Entre las actividades que se diseñaron para Facebook, se les pidió que describieran cómo se imaginaban a Sara, la protagonista, y que la dibujaran o buscaran imágenes en la internet que se acercaran a la imagen mental que tenían de ella. Otra actividad requirió que investigaran algunos aspectos de la novela para determinar si eran reales o ficticios. También se les pidió que publicaran una imagen que representara su reacción a una revelación importante a la mitad del libro. Por último, se les pidió que generaran un final alternativo para la obra.

Las actividades del círculo de lectura enriquecido constituyeron espacios para explorar otros tipos de intertextualidades transmedia no cubiertos por la propia obra, como la imitación, la reproposición (Repurposing), la inconsistencia y la generación.

Aunque el pretexto para este círculo de lectura enriquecido fue una novela transmedia, después de realizarlo quedó claro que la metodología funcionaría igualmente si la obra leída no fuera transmedia. Sin embargo, la experiencia lo seguiría siendo, mientras mantuviera el uso de diferentes medios, como en este caso Facebook y la propia Red.

El docente puede generar una experiencia educativa transmedia a partir de diferentes contenidos que no necesariamente fueron producidos para funcionar en una lógica transmedia, pero también puede diseñar 
actividades que permitan que la lectura y la creación de los estudiantes fluyan entre diferentes medios.

Otro punto importante a considerar es que estas experiencias no se ajustan a las reglas de las narrativas de ficción, pues pueden y a veces deben ser redundantes. Con relación a esto, Teske y Horstman (2012) mencionan como un propósito importante de lo transmedia, lo que denominan "comprensión aditiva", en la que cada nuevo texto suma a nuestro entendimiento de una historia como un todo.

Un aspecto a enfatizar es la noción de experiencia, ya que lo transmedia, como afirman Teske y Horstman, incluye la cocreación de los lectores, su involucramiento como coproductores. El docente puede generar oportunidades para que se dé esta participación creativa en diferentes formatos y soportes.

Al igual que Zorrilla (2008; 2016a) y Zorrilla, Cruz y Hernández (2016), Montoya y Arango (2015) también proponen la intertextualidad como la piedra angular que posibilita las experiencias educativas transmedia, a través de la lectura y la escritura en diferentes formatos. En este sentido, la lectura transmedia y la generación de experiencias al estilo fanfic entre los estudiantes origina textos en diferentes formatos, lo que a su vez permite la adquisición y desarrollo de habilidades que forman parte de la cultura digital. Scolari propone el término de alfabetismo transmedia para referirse a estas nuevas habilidades que se desarrollan a partir de experiencias transmedia:

En este contexto, el alfabetismo transmedia se entiende como un conjunto de habilidades, prácticas, valores, sensibilidades y estrategias de aprendizaje e intercambio desarrolladas y aplicadas en el contexto de la nueva cultura colaborativa. Si la alfabetización tradicional estaba centrada en el libro -o, en el caso de la alfabetización mediática, especialmente en la televisión- la alfabetización transmedia coloca a las nuevas experiencias mediáticas digitales e interactivas en el centro de su propuesta analítica y práctica. Pero una nueva concepción del alfabetismo no puede limitarse a los soportes materiales. Si las formas tradicionales de alfabetismo interpelaban a los sujetos principalmente como iletrados (un sujeto 'ni-ni', que no escribe ni lee) o consumidores (lectores, espectadores), el alfabetismo transmedia los considera 'prosumidores' (productores + consumidores) (Scolari, 2016, p. 8). 


\section{Conclusión}

En lo que toca a la creación y el consumo de productos transmedia, el trabajo realizado a la fecha permite identificar diversas formas de involucramiento del público meta, desde la lectura, con sus diversas prácticas y trayectorias en el transitar a través de los componentes mediáticos de la obra, hasta su participación en la cocreación de la misma.

Las intertextualidades transmedia fluyen entre lo físico y lo digital, en experiencias que hoy algunos denominan figitales (phygital).

Hoy por hoy, estos flujos en el ámbito educativo no dependen de las empresas productoras de contenidos, que poco han incursionado en lo transmedia, al menos en México. Dependen principalmente de los docentes, quienes tienen la posibilidad de diseñar experiencias transmedia, no solo a partir de las intersecciones entre diferentes contenidos ya existentes en variados soportes mediáticos, sino también a partir del uso y aprovechamiento de los diversos canales hoy disponibles y de las prácticas y herramientas que usan los estudiantes, como las redes sociales. Es importante recalcar que estas experiencias pueden perfectamente fluir entre lo físico y lo digital, entre lo presencial y lo virtual.

El diseño de experiencias educativas transmedia implica pensar en contenidos transmedia, pero también en actividades transmedia, y en estas últimas el componente de la creación, de la expresión en diferentes soportes y formatos mediáticos, es clave para lograr un doble aprendizaje, el del tema objeto de la experiencia transmedia y el desarrollo de la propia literacidad transmedia como un aprendizaje transversal.

Las actividades transmedia detonan en los jóvenes habilidades e inquietudes que son propias de su cultura digital, como la representación y la apropiación (Jenkins, 2009).

Hoy día, en México y otros países de similar nivel de desarrollo, la incorporación de lo transmedia en la educación depende en gran medida de la creatividad de los docentes para descubrir intertextualidades transmedia entre productos aparentemente no relacionados entre sí, como puede ser el propio libro de texto y una película comercial y diseñar rutas para su 
exploración, así como para crear actividades de aprendizaje que involucren la lectura y, sobre todo, la escritura en diferentes medios y formatos, concebida esta última en un sentido amplio para abarcar diversas formas de expresión que van desde la palabra escrita, hasta el video, pasando por la fotografía, el dibujo, la ilustración, el arte dramático, la danza y la composición musical, por mencionar solo algunas.

Falta mucho por hacer y por descubrir en materia de usos y aprovechamiento de lo transmedia en la esfera educativa. Lo aquí presentado es solo un atisbo. 


\section{Referencias}

Jenkins, H. (2003, enero 15). Transmedia Storytelling. MIT Technology Review [en línea]. Recuperado de https://bit.ly/22v1yRK

Jenkins, H. (2006). Convergence Culture: Where Old and New Media Collide. Nueva York, NY: New York University Press.

Jenkins, H., Purushotma, R., Weigel, M., Clinton, K., \& Robison, A. J. (2009). Confronting the Challenges of Participatory Culture: Media education for the 21st century. Cambridge, MA; Londres, Inglaterra: MIT Press. Disponible en https://bit.ly/2ENQPLi

Jenkins, H., Ford, S., \& Green, J. (2013). Spreadable Media. Creating value and meaning in a networked culture. Nueva York, NY: New York University Press.

Kinder, M. (1991). Playing with Power in Movies, Television, and Video Games: from Muppet Babies to Teenage Mutant Ninja Turtles. Berkeley, CA: University of California Press.

Montoya Bermúdez, D. y Arango Marín, M. (2015). Los sistemas intertextuales transmedia como estrategia pedagógica: De The Walking Dead ${ }^{\circledR}$ a La Odisea. Correspondencia Æ̊ Análisis, (5), 15-36. doi: https:// doi.org/10.24265/cian.2015.n5.01

Pratten, R. (2011). Getting Started with Transmedia Storytelling: A practical guide for beginners. [Publicación del autor]. Disponible en https://bit. $1 \mathrm{y} / 2 \mathrm{p} 0 \mathrm{QFwG}$

Scolari, C. A. (2009). Transmedia Storytelling: Implicit Consumers, Narrative Worlds, and Branding in Contemporary Media Production. International Journal of Communication, (3), 586-606. Recuperado de https://bit.ly/2SaZ8Zd

Scolari, C. A. (2016). Estrategias de aprendizaje informal y competencias mediáticas en la nueva ecología de la comunicación. Telos. Revista de Pensamiento sobre Comunicación, Tecnología y Sociedad, (103), 13-23. Recuperado de https://bit.ly/2QZEqLq 
Teske, P., \& Horstman, T. (2012). Transmedia in the classroom: breaking the fourth wall. En A. Lugmayr, \& Association for Computing Machinery, Proceeding of the 16th International Academic MindTrek Conference (pp. 5-9). Nueva York, NY: ACM. Disponible en https://bit.ly/2V0vOGT

Zorrilla Abascal, M. L. (2008). Educational Television Beyond the TV set: Educational Media Convergence in the UK and a Proposal for the Mexican Model (tesis doctoral). University of East Anglia, Norwich, Inglaterra. Disponible en https://bit.ly/2rLFIyz

Zorrilla Abascal, M. L. (2011). BBC Schools Beyond the TV Set: Educational Media Convergence in the Classroom. En E. Dunkels, G. Franberg, \& C. Hallgren (Eds.), Interactive Media Use and Youth: Learning, Knowledge Exchange and Behavior (pp. 119-148). Hershet, PA: Information Science Reference. Disponible en https://bit.ly/2SWw7QU

Zorrilla Abascal, M. L. (2014). La flauta de Acuario. Una novela transmedia. México: Universidad Autónoma del Estado de Morelos; Conaculta. Disponible en http://karmaq.mx/, http://diario.karmaq.mx/, http://duo. karmaq.mx/

Zorrilla Abascal, M. L. (2016a). Transmedia intertextualities in educational media resources: The case of BBC Schools in the United Kingdom. New Media \& Society, 18(11), 2629-2648. doi: 10.1177/1461444815590140 Zorrilla Abascal, M. L. (2016b). Transmedia: sustantivo o adjetivo. Ponencia presentada en XXIV Encuentro Internacional de Educación a Distancia, Guadalajara, Jal, 28 de noviembre al 2 de diciembre de 2016.

Zorrilla Abascal, M. L., Cruz, C., y Hernández, I. (2016). Leer, compartir y reflexionar una novela transmedia en un círculo de lectura enriquecido. Ponencia presentada en el XVI Encuentro Internacional Virtual Educa, Puerto Rico, 2016. Disponible en https://bit.ly/2EG9Kfw 